\title{
Relationship between glycemic control and perceived family support among people with type 2 diabetes mellitus seen in a rich kinship network in Southwest Nigeria
}

\author{
Nnenna A. Osuji ${ }^{1}$, Oluwaseun Solomon Ojo ${ }^{1}$, Sunday O. Malomo ${ }^{1}$, Peter T. Sogunle ${ }^{1}$, Ademola O. Egunjobi ${ }^{1}$, \\ Olufisayo O. Odebunmi ${ }^{1}$
}

\begin{abstract}
Objective: The practice of diabetes self-care behaviors has been cited as a foundation for achieving optimal glycemic control. Proper motivation of people with diabetes mellitus is, however, needed for the performance of these behaviors. It is therefore pertinent to know if motivation by the family will improve glycemic control in people with type 2 diabetes mellitus. This study aimed to investigate the relationship between glycemic control and perceived family support among Nigerians with type 2 diabetes mellitus.
\end{abstract}

Methods: A cross-sectional study was conduced on 316 adults with type 2 diabetes mellitus who attended a medical outpatient clinic. Data were collected through a pretested intervieweradministered questionnaire and a standardized tool (Perceived Social Support - Family scale). Hemoglobin $\mathrm{A}_{1 \mathrm{c}}$ level was used as an indicator of glycemic control.

Results: The proportion of participants with good glycemic control was $40.6 \%$. Most of the participants $(137,43.8 \%)$ had strong perceived family support. Strong perceived family support ( $P=0.00001$, odds ratio 112.51) was an independent predictor of good glycemic control.

Conclusion: This study shows that strong perception of family support is a predictor of glycemic control among the adults with type 2 diabetes mellitus studied. Physicians working in subSaharan African countries with rich kinship networks should harness the available family support of people with type 2 diabetes mellitus in their management.

Keywords: Glycaemic control; perceived family support; type 2 DM; kinship; Nigeria

Significance statement: Nigeria and other sub-Saharan African countries are currently experiencing a rapid increase in the incidence of noncommunicable diseases, especially diabetes mellitus (DM), as a result of increasing urbanization and changing lifestyles. People with diseases such as DM that require lifelong management may be tired of taking medications and adhering to the lifestyle modifications over time. This underscores the importance of motivation in people with DM. Can support from the family motivate people with DM to improve self-management behaviors and ultimately their glycemic control?

Few studies have looked at the relationship between perceived family support and glycemic control among people with type 2 DM. The conclusions from these studies did not point in any specific direction. Most of these studies were also done in developed countries. Thus, assessing the relationship between perceived family support and glycemic control in a setting with a rich kinship network may give better insight into this theme.
1. Family Medicine Department, Federal Medical Centre, Abeokuta, Nigeria

CORRESPONDING AUTHOR

Dr. Oluwaseun Solomon Ojo Department of Family Medicine, Federal Medical Centre, Abeokuta, +234 Ogun State, Nigeria

Tel.: +234-8035020964

E-mail: ojo_teenager@yahoo.com

Received 5 April 2018; Accepted 5 July 2018 


\section{Introduction}

Diabetes mellitus (DM) is on the rise around the globe [1]. Globally, DM affects more than 425 million people, and the number of people with DM may rise to 693 million in 2045 if nothing is done [1]. In 2017, Nigeria ranked fourth in Africa, with 1.2 million to 3.9 million people affected by DM [1]. The continuous rise in the prevalence of DM has been associated with the consequent increase in the proportion of people with uncontrolled glycemia. Evidence in most studies suggests that less than $50 \%$ of DM patients achieve glycemic targets [2-4].

DM has been described as a "family disease" because of the complex association of all aspects of diabetes with family dynamics $[5,6]$. Familial risk has been implicated in the development of type 2 DM (T2DM) [1]. The emerging epidemic of DM in Africa has been attributed to the industrialization-driven disruption of the African extended family system through rural-urban migration and consequent unhealthy lifestyles [1]. The family is also a useful unit of intervention for chronic diseases such as DM [5-8].

DM is a lifelong disease that requires care within and outside the hospital. The care beyond the hospital wall, which is mainly self-care behaviors, is central to DM management [9, 10]. This is more relevant to DM care in Nigeria, where, in the face of the astronomically increased number of DM patients, there is poor health care use as well as a low physician-patient ratio [11]. Self-care practices require behavioral change on the part of patients, and this may be an arduous task without motivation. The institution from where DM patients can get motivation is the family $[12,13]$. Could the solution to poor glycemic control among DM patients be support from their families?

The results of studies on the relationship between family support and glycemic control among people with DM have not been consistent [5-8, 14, 15]. Some studies have shown that family support improves glycemic control among people with DM [8, 14], while another study has reported no effect on glycemic control among them [15]. However, most of these studies were not conducted in Africa, where the family is rated high in the value system [5-7, 14, 15]. In addition, most of these studies did not assess perceived family support, which predicts better health outcomes [14, 15].

Thus, it is pertinent to look at the relationship between glycemic control and perceived family support in a traditional African setting, where the extended family system is still very common. This study is based on this premise that the authors sought to investigate the relationship between glycemic control and perceived family support among people with T2DM seen in a tertiary hospital located in a rich kinship network in southwest Nigeria.

\section{Research design and methods \\ Study site}

This study was conducted in the medical outpatient clinic of a tertiary hospital in southwest Nigeria. The medical outpatient clinic is one of the specialist clinics that serve as a receiving center for referrals mainly from the general outpatient clinic and other units of the hospital. Health education is given by the nurses and dieticians especially for people with DM and hypertension on each clinic day. Adult male and female patients, including new patients and patients returning for routine follow-up visits, are seen at the clinic.

\section{Study population}

The study population comprised adults aged 18 years or older with T2DM attending the medical outpatient clinic of a tertiary hospital in southwest Nigeria.

\section{Inclusion and exclusion criteria}

All consenting adults with T2DM aged 18 years or older who had been attending the medical outpatient clinic for DM care for at least 1 year were included in the study. Patients with psychiatric illness and critically ill patients were excluded.

\section{Sample size}

The sample size was determined with the formula for estimating prevalence from a descriptive study: $n=z^{2} p q / d^{2}$ [16]. A sample size of 316 was obtained with standard normal deviate $(z)=1.96$, the proportion of people with T2DM with good glycemic control from a previous study ( $p$ ) of $29.3 \%$ (0.293) [17], and desired level of precision $(d)=0.05$.

\section{Sampling technique}

A systematic random sampling technique was used to recruit 316 participants for this study until the sample size was reached. The case files of those selected at the end of each clinic were marked with a sticker to avoid duplication. 


\section{Data collection}

A pretested interviewer-administered questionnaire and a standardized questionnaire were used to collect information on sociodemographic characteristics and the level of perceived family support of the respondents, respectively. Study participants were interviewed alone, without a family member present, by the investigators. The questionnaire consisted of sections on sociodemographic data, information on the level of perceived family support, and blood glucose control. Sociodemographic characteristics consisted of information pertaining to age, sex, marital status, type of family, household size, education level, religion, and ethnic group.

The respondents' level of perceived family support was assessed with the Perceived Social Support - Family scale of Procidano and Heller [18]. It is a 20-item validated selfreport scale which examines how people perceive support, information, and response from their family. Respondents answered "Yes," "No," or "I don't know" to each question. Each "yes" answer was scored as 1 , while other responses were scored 0 . Items 3, 4, 16, 19, and 20 were reverse scored (a "no" response was scored as 1). Summated scores were used to arrive at a perceived family support score, and the possible range of scores was 0-20. Scores were categorized as strong perceived family support $(\geq 11)$, weak perceived family support (7-10), and no perceived family support $(\leq 6)$. The scale has acceptable validity and reliability. The internal consistency of the scale is 0.88 , while the short-term test-retest reliability is 0.83 [18].

Glycemic control was assessed by measurement of glycated hemoglobin (hemoglobin $\mathrm{A}_{1 \mathrm{c}}$ ) levels. Three milliliters of a venous blood sample for measurement of hemoglobin $A_{1 c}$ level was drawn from the antecubital vein of each participant into a fluoride sample bottle. Hemoglobin $A_{1 c}$ level was determined by the rapid ion exchange chromatographic method (DIALAB, Gieselhaft, Germany). The blood samples were stored at $2{ }^{\circ} \mathrm{C}-$ $8^{\circ} \mathrm{C}$ and the analysis was done within 5 days of collection. The following formula given by the manufacturer of the kit was used to obtain the Diabetes Control and Complications Trial referenced values: National Glycohemoglobin Standardization Program hemoglobin $\mathrm{A}_{1 \mathrm{c}}$ level $(\%)=0.86 \times$ DIALAB hemoglobin $\mathrm{A}_{1 \mathrm{c}}$ level $(\%)+0.24$. Glycemic control was categorized on the basis of the American Diabetes Association criteria as good glycemic control (hemoglobin $\mathrm{A}_{1 \mathrm{c}}$ level $<7 \%$ ) and poor glycemic control (hemoglobin $A_{1 c}$ level $\geq 7 \%$ ) [19].

\section{Data analysis}

IBM SPSS Statistics (IBM, Armonk, NY, USA) version 22.0 was used for data analysis. Figures and tables were drawn to present data. Means and standard deviations were calculated for continuous variables, while ratios and percentages were calculated for categorical variables as appropriate. The chi-square test was used to test the association between the categorical variables. The level of significance was set at $P \leq 0.05$. Significant independent variables were entered into a logistic regression analysis to determine the independent predictors of glycemic control. The odds ratios (ORs) and 95\% CIs for the predictor variables were then calculated.

\section{Ethical considerations}

Ethics approval was obtained from the Health Research Ethics Committee of the Federal Medical Center, Abeokuta with reference approval number NREC/08/04/2010. Consent was also obtained from the patients.

\section{Results}

A total of 316 participants were recruited from the medical outpatient clinic for the study. Three participants had missing data that precluded analysis; hence data for 313 participants were analyzed, giving a completion rate of $99.05 \%$.

Table 1 shows the sociodemographic characteristics of the study participants. The age range of the respondents was $34-86$ years. The mean age was $60.96 \pm 10.1$ years. Most of the respondents were in the 45-64 year age group (163, $52.1 \%)$. There were more female respondents $(185,59.1 \%)$ than male respondents $(128,40.9 \%)$, with a male-to-female ratio of $1: 1.5$.

Of the 313 T2DM patients for whom data were analyzed, $43.8 \%$ (137) had strong perceived family support, $40.9 \%$ (128) had weak perceived family support, and $15.3 \%$ (48) had no perceived family support (Fig. 1).

Figure 2 shows the level of glycemic control among the participants. Most of them had poor glycemic control (186, $59.7 \%$ ), while $40.6 \%$ (127) had good glycemic control. 
Table 1. Sociodemographic characteristics of the respondents

\begin{tabular}{|c|c|c|c|}
\hline Variable & Category & Number & Percentage \\
\hline \multirow[t]{2}{*}{ Sex } & Male & 128 & 40.9 \\
\hline & Female & 185 & 59.1 \\
\hline \multirow[t]{4}{*}{ Age group } & Young (18-44 years) & 16 & 5.1 \\
\hline & Middle-aged & 163 & 52.1 \\
\hline & (45-64 years) & & \\
\hline & Elderly ( $\geq 65$ years) & 134 & 42.8 \\
\hline \multirow[t]{4}{*}{ Ethnicity } & Yoruba & 304 & 97.1 \\
\hline & Igbo & 5 & 1.6 \\
\hline & Hausa & 0 & 0.0 \\
\hline & Other & 4 & 1.3 \\
\hline \multirow[t]{5}{*}{ Marital status } & Single & 1 & 0.3 \\
\hline & Married & 272 & 86.9 \\
\hline & Separated & 5 & 1.6 \\
\hline & Divorced & 5 & 1.6 \\
\hline & Widowed & 30 & 9.6 \\
\hline \multirow[t]{2}{*}{ Type of family } & Monogamous & 249 & 79.6 \\
\hline & Polygamous & 64 & 20.4 \\
\hline \multirow[t]{2}{*}{ Household size } & $\leq 5$ & 119 & 38.0 \\
\hline & $>5$ & 194 & 62.0 \\
\hline \multirow[t]{4}{*}{ Level of education } & No formal education & 46 & 14.7 \\
\hline & Primary & 73 & 23.3 \\
\hline & Secondary & 72 & 23.0 \\
\hline & Tertiary & 122 & 39.0 \\
\hline \multirow[t]{3}{*}{ Religion } & Christianity & 236 & 75.4 \\
\hline & Islam & 76 & 24.3 \\
\hline & Traditional belief & 1 & 0.3 \\
\hline \multirow[t]{6}{*}{ Occupation } & Unemployed & 10 & 3.2 \\
\hline & Retired & 58 & 18.5 \\
\hline & Artisan & 32 & 10.2 \\
\hline & Trader & 109 & 34.8 \\
\hline & Civil servant & 85 & 27.2 \\
\hline & Other & 19 & 6.1 \\
\hline \multirow{4}{*}{$\begin{array}{l}\text { Monthly earnings } \\
\text { (naira) }\end{array}$} & $<10,000$ & 60 & 19.2 \\
\hline & $10,000-50,000$ & 120 & 38.3 \\
\hline & $51,000-100,000$ & 87 & 27.8 \\
\hline & $>100,000$ & 46 & 14.7 \\
\hline
\end{tabular}

Bivariate analysis of the association of sociodemographic factors with glycemic control showed that age $\left(\chi^{2}=10.550, P=0.005\right)$ and $\operatorname{sex}\left(\chi^{2}=15.905, P=0.000067\right)$ were statistically significantly associated with glycemic control (Table 2).
Pattern of perceived family support

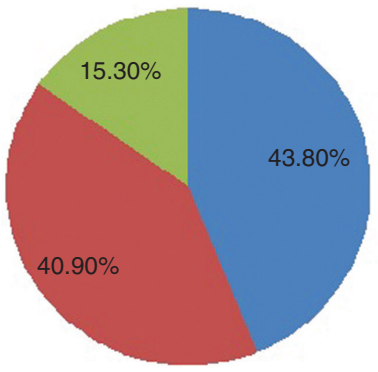

$\backsim$ Strong perceived family support -Weak perceived family support No perceived family support

Fig. 1. Pie chart showing the pattern of perceived family support among the respondents.

The Perceived Social Support - Family scale of Procidano and Heller was used to assess the level of perceived family support of the respondents. It is a 20 -item validated self-report scale. Summated scores were used to arrive at a perceived family support score, and the possible range of scores is $0-20$. The score was categorized as strong family support $(\geq 11)$, weak family support (7-10), and no family support $(\leq 6)$. Of the 313 respondents, $43.8 \%$ had good perceived family support, $40.9 \%$ had weak perceived family support, and $15.3 \%$ had no perceived family support.

Pattern of glycaemic control among respondents

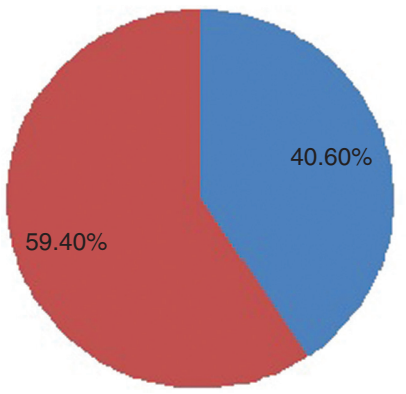

Good glycemic control

- Poor glycemic control

Fig. 2. Pie chart showing the pattern of glycemic control among the respondents.

Respondents with a hemoglobin $\mathrm{A}_{1 \mathrm{c}}$ level of $7 \%$ or greater $(\geq 53 \mathrm{mmol} /$ mol) were regarded as having poor glycemic control, while respondents with a hemoglobin $\mathrm{A}_{1 \mathrm{c}}$ level below $7 \%(<53 \mathrm{mmol} / \mathrm{mol})$ were regarded as having good glycemic control. Among the 313 respondents, $40.6 \%$ had good glycemic control and 59.4\% had poor glycemic control.

Perceived family support was also significantly associated with glycemic control $\left(\chi^{2}=134.164, P=0.00001\right)$ (Table 3). The independent predictor of glycemic control in this study 
Table 2. Relationship between glycemic control and sociodemographic factors

\begin{tabular}{|c|c|c|c|c|c|c|}
\hline Variable & Category & $\begin{array}{r}\text { Good glycemic } \\
\text { control }\left(\mathrm{HbA}_{1 \mathrm{c}}<7 \%\right. \\
\text { or }<53 \mathrm{mmol} / \mathrm{mol})\end{array}$ & $\begin{array}{r}\text { Poor glycemic } \\
\text { control }\left(\mathrm{HbA}_{1 \mathrm{c}} \geq 7 \%\right. \\
\text { or } \geq 53 \mathrm{mmol} / \mathrm{mol})\end{array}$ & $\chi^{2}$ & df & $P$-value \\
\hline \multirow[t]{2}{*}{ Sex } & Male & $42(32.8)$ & $86(67.2)$ & 15.905 & 1 & 0.000067 \\
\hline & Female & $103(55.7)$ & $82(44.3)$ & & & \\
\hline \multirow[t]{3}{*}{ Age group } & Young (18-44 years) & $5(31.2)$ & $11(68.8)$ & 10.550 & 2 & 0.005 \\
\hline & Middle aged (45-64 years) & $64(39.3)$ & $99(60.7)$ & & & \\
\hline & Elderly ( $\geq 65$ years) & $76(56.7)$ & $58(43.3)$ & & & \\
\hline \multirow[t]{5}{*}{ Marital status } & Single & $0(0.0)$ & $1(100.0)$ & 5.180 & 4 & 0.269 \\
\hline & Married & $121(44.5)$ & $151(55.5)$ & & & \\
\hline & Divorced & $2(40.0)$ & $3(60.0)$ & & & \\
\hline & Separated & $3(60.0)$ & $2(40.0)$ & & & \\
\hline & Widowed & $17(56.7)$ & $13(43.3)$ & & & \\
\hline \multirow[t]{2}{*}{ Family type } & Monogamous & 101(40.6) & $148(59.6)$ & 0.048 & 1 & 0.827 \\
\hline & Polygamous & $25(39.1)$ & $39(60.9)$ & & & \\
\hline \multirow[t]{2}{*}{ Household size } & $\leq 5$ & $55(46.2)$ & $64(53.8)$ & 0.001 & 1 & 0.976 \\
\hline & $>5$ & $90(46.4)$ & $104(53.6)$ & & & \\
\hline \multirow[t]{4}{*}{ Level of education } & No formal education & $19(41.3)$ & $27(58.7)$ & 1.902 & 3 & 0.593 \\
\hline & Primary & $31(42.5)$ & $42(57.5)$ & & & \\
\hline & Secondary & $33(45.8)$ & $39(54.2)$ & & & \\
\hline & Tertiary & $62(50.8)$ & $60(49.2)$ & & & \\
\hline \multirow[t]{6}{*}{ Occupation } & Unemployed & $5(50.0)$ & $5(50.0)$ & 8.493 & 5 & 0.131 \\
\hline & Retired & $35(60.3)$ & $23(39.7)$ & & & \\
\hline & Artisan & $15(46.8)$ & $17(53.2)$ & & & \\
\hline & Trader & $48(44.0)$ & $61(56.0)$ & & & \\
\hline & Civil servant & $34(40.0)$ & $51(60.0)$ & & & \\
\hline & Other & $6(31.6)$ & $13(68.4)$ & & & \\
\hline \multirow[t]{4}{*}{ Monthly earnings (naira) } & $<10,000$ & $35(58.3)$ & $25(41.7)$ & 5.123 & 4 & 0.275 \\
\hline & $10,000-50,000$ & $54(45.0)$ & $66(55.0)$ & & & \\
\hline & $51,000-100,000$ & $44(50.6)$ & $43(49.4)$ & & & \\
\hline & $>100,000$ & $17(37.0)$ & $29(63.0)$ & & & \\
\hline
\end{tabular}

df, degrees of freedom; $\mathrm{HbA}_{1 \mathrm{c}}$, hemoglobin $\mathrm{A}_{1 \mathrm{c}}$.

was strong perceived family support $(P=0.00001, \mathrm{OR}=112.51$, 95\% CI $=46.638-271.440$ ) (Table 4).

\section{Discussion}

The age distribution depicted by this study with more than $90 \%$ of the respondents in the middle-aged and elderly age groups typifies the age of patients with T2DM seen in Nigeria. Old age is a universally recognized risk factor for the development of DM and other chronic diseases [1, 8, 20, 21]. In the typical patient with T2DM seen in Nigeria, T2DM is diagnosed in the fifth to sixth decade of life $[8,20,21]$. This finding underscores the importance of health promotion through lifestyle changes and screening programs for Nigerians who are aged 40 years or older.

About $59.4 \%$ of the participants had poor glycemic control. Available local and international literature on the level of glycemic control among T2DM patients also revealed poor glycemic control [2-4, 8, 20-23]. The largest multicenter 
Table 3. Relationship between glycemic control and perceived family support of the respondents

\begin{tabular}{|c|c|c|c|c|c|}
\hline Category & $\begin{array}{r}\text { Good glycemic control }\left(\mathrm{HbA}_{1 \mathrm{c}}\right. \\
<7 \% \text { or }<53 \mathrm{mmol} / \mathrm{mol})\end{array}$ & $\begin{array}{r}\text { Poor glycemic control }\left(\mathrm{HbA}_{1 \mathrm{c}}\right. \\
\geq 7 \% \text { or } \geq 53 \mathrm{mmol} / \mathrm{mol})\end{array}$ & $\chi^{2}$ & df & $P$-value \\
\hline Strong support & $114(83.2 \%)$ & $23(16.8 \%)$ & 134.164 & 2 & 0.00001 \\
\hline Weak support & $19(14.8 \%)$ & $109(85.2 \%)$ & & & \\
\hline No support & $12(25.0 \%)$ & $36(75.0 \%)$ & & & \\
\hline
\end{tabular}

df, degrees of freedom; $\mathrm{HbA}_{1 \mathrm{c}}$, hemoglobin $\mathrm{A}_{1 \mathrm{c}}$.

Table 4. Logistic regression analysis of significant factors associated with glycemic control

\begin{tabular}{llrrrr}
\hline Variable & Category & $\beta$ & $P$-value & Odds ratio & $95 \%$ Cl \\
\hline Sex & Female & -0.642 & 0.100 & 0.526 & $0.245-1.131$ \\
& Male & & & 0.538 & $0.111-2.607$ \\
Age group & Elderly ( $\geq 65$ years) & -0.620 & 0.441 & 0.375 & $0.075-1.875$ \\
& Middle-aged (45-64 years) & -0.980 & 0.232 & 112.51 & $46.638-271.440$ \\
& Young (18-44 years) & & & 0.00001 & \\
\hline
\end{tabular}

CI, confidence interval.

descriptive cross-sectional study (2352 T2DM patients) conducted in six sub-Saharan African countries to study the quality of glycemic control and coexisting DM-related complications (the Diabetes Africa Study) reported good glycemic control in only $29.0 \%$ of the study participants [23]. Similarly, in a multicenter study that involved seven tertiary hospitals across the six geopolitical zones in the country (Diabetic Care Nigeria Study), less than one-third of patients studied attained the guideline-recommended glycemic targets of a hemoglobin $\mathrm{A}_{1 \mathrm{c}}$ level less than $7.0 \%$ and a mean hemoglobin $\mathrm{A}_{1 \mathrm{c}}$ value of $(8.3 \pm 2.2) \%[3,21]$.

In general, the low rate of optimal glycemic control among DM patients has been attributed to poor adherence to antidiabetic medications and financial constraints [3, 21, 24]. Poor adherence in a resource-poor country such as Nigeria may be due to poverty. Thus, financial constraints may be a key factor responsible for poor glycemic outcome seen in Nigeria. In addition, the small percentage of Nigerians with DM (less than $10.0 \%$ who are members of the National Health Insurance Scheme or any other insurance scheme makes patients bear the cost of care at a price that is much higher than the cost of these services in other parts of the world $[3,21]$. Thus, support from family members may assist in relieving DM patients of the huge financial burden of care.

This study showed that older patients had better glycemic control than younger patients. Achievement of glycemic control among patients older than 65 years was greater than that among the other age groups. This is consistent with the findings of other studies [25, 26]. The US National Health and Nutrition Examination Survey 2007-2010 reported that glycemic control was best among those aged 65 years or older and worst among those aged 18-39 years [26]. Ahmad et al. [25] reported that an increase in age of 1 year was associated with a $3 \%$ increase in the likelihood of achieving targeted glycemic control. Being elderly may attract support from family members in terms of elderly people being reminded of their medications, clinic attendance, and lifestyle. This might play a role in increasing adherence in elderly people, and thus could have contributed to the better glycemic control among them.

Contrary to the finding in this study, Ewenighi et al. [27] in a study conducted in Edo state, Nigeria, reported that younger 
people with T2DM are more likely to have better glycemic control than elderly people. The difference between the finding in this study and the Edo study could be attributed to the study design. The Edo study was an interventional study where the study participants were subjected to the same 20-week glycemic control therapy involving oral medication (metformin) and lifestyle intervention (diet), which ultimately reduced the issue of nonadherence [27].

The finding of more females achieving good glycemic control than males in this study is in keeping with the findings of most studies that investigated the influence of sex on glycemic control [28, 29]. Many factors may have contributed to this observation. Firstly, the likelihood of being screened for $\mathrm{DM}$ is higher in women than in men because of more contact with health facilities during the reproductive years. Secondly, women are more inclined to have better health-seeking behavior, adhere to regular follow-up, and have a more adaptive attitude toward DM [30]. However, better glycemic control in males has been reported. This is especially from a study done in an area where the socioeconomic status of women is poor [31]. Considering the inconsistent findings on the influence of sex on glycemic control, interventional approaches should go beyond sex differences in glycemic control. They should be focused on improving patients' and family members' understanding of the disease.

Although the traditional African family structure is gradually being eroded as a result of urbanization [32], the finding of more than two-fifths of respondents having strong perceived family support and less than one-fifth of respondents having no perceived family support agrees with the fact that Africans have a naturally rich social support network [33]. This result is comparable to the findings in southwest Nigeria of Adetunji et al. [8], who reported that $49 \%$ of the people with T2DM studied had strong perception of family support. The strong family and kinship ties as expressed in daily life and interactions that are inherent in African culture may explain the high rate of strong perceived family support seen in this study. The great number of married and elderly respondents in the study may also be responsible for the high level of strong perceived family support in this study. It is known that married and older people are more likely to report better perception of family support than younger people $[8,34,35]$.
This study showed that strong perceived family support is an independent predictor of good glycemic control and that respondents with strong perceived family support were approximately 112 times more likely to have good glycemic control than respondents without strong perceived family support $(\mathrm{OR}=112.51,95 \% \mathrm{CI}=46.638-271.440)$. There is a lack of agreement in the literature on the effect of perceived family support on glycemic control in DM patients. Generally, most studies reported better self-care behavior among DM patients with strong family support without corresponding improvement in glycemic control [36, 37]. A systematic study also showed that health outcomes in patients with uncontrolled glycemia can be improved only when family support is integrated with DM self-management [38].

The variation in the relationship between family support and health outcomes in DM may be due to the varying family pattern norms in different parts of the world. While this study and other African studies [7, 8, 20] showed a positive relationship between family support and glycemic control, studies done outside Africa showed no specific direction [36, 37, 39]. A typical African family has been described to be mostly rural, polygamous, and open to kinship networks [40]. The naturally rich social networks seen in Africans may explain the positive influence of family support on glycemic control among Africans.

The present study has contributed to the evidence on the positive influence of perceived family support on glycemic control among African T2DM patients. In the face of the evolving changes in sub-Saharan African family structure due to modernization, the family still remains an important tie in the social life of Africans. The belief in collectivism, as opposed to individuality that is entrenched in the traditional African family system, ensures that patients with chronic diseases such as DM receive support from their family and friends.

Family support is important in the long-term management of DM, which requires a lifelong change in the lifestyle of the affected person. Strong perceived family support will improve their self-worth and motivation. It is plausible that a motivated person with DM will adhere to therapeutic plans and therefore achieve better glycemic control. It is essential that health care providers involve families of people with DM in their 
management so as to improve patients' function and treatment outcome. More importantly, physicians should use an integrated approach that incorporates family engagement into T2DM self-management models. Future research in this area should include randomized controlled trials on the influence of family support on self-care behavior and glycemic control among people with T2DM.

The following limitations were considered in this study. Firstly, this was a hospital-based study, and thus the results may not be generalizable to all people with DM. Secondly, as a result of the cross-sectional design of this study, the findings from it cannot address issues of causal relationships between glycemic control and the factors found to be associated with it. The study relied on a questionnaire to elicit information from the respondents. The responses could be subjective and may not reflect the actual perception of family support.

\section{Conclusion}

This study showed that sex, age group, and perceived family support were significantly associated with glycemic control. Among the three variables that were associated with glycemic control, strong perceived family support was the only independent predictor of good glycemic control among people with T2DM. This study implies that the perception of family support may be of value to African patients with T2DM in achieving optimal glycemic control. Physicians working in sub-Saharan African countries with rich kinship networks should harness the available family support of people with T2DM in their management.

\section{Acknowledgments}

We especially thank all our colleagues in the Department of Family Medicine for their contributions during the preparation of this work.

\section{Conflict of interest}

The authors declare no conflict of interest.

\section{Funding}

Financing of the project was borne by the researchers. There were no direct or indirect monetary costs for the study participants.

\section{Author contributions}

Nnenna Angelina Osuji, Oluwaseun Solomon Ojo Peter Taiwo Sogunle, and Olukayode Sunday Malomo conceptualized the study. Nnena Angelina Osuji, Oluwaseun Solomon Ojo, Sunday Olukayode Malomo, Peter Taiwo Sogunle, Ademola Oluwaseun Egunjobi, and Olufisayo Oyewe Odebunmi designed the research. Nnena Angelina Osuji, Oluwaseun Solomon Ojo, Sunday Olukayode Malomo, Peter Taiwo Sogunle, Ademola Oluwaseun Egunjobi, and Olufisayo Oyewe Odebunmi collected and analyzed the data. Nnena Angelina Osuji, Oluwaseun Solomon Ojo, Sunday Olukayode Malomo, Taiwo Peter Sogunle, Ademola Oluwaseun Egunjobi and Olufisayo Oyewe Odebunmi wrote the paper. Nnenna Angelina Osuji, Oluwaseun Solomon Ojo, Sunday Olukayode Malomo, Peter Taiwo Sogunle, Ademola Oluwaseun Egunjobi, and Olufisayo Oyewe Odebunmi edited the paper. All authors read and approved the final article.

\section{References}

1. International Diabetes Federation. IDF diabetes atlas - 8th edition. Brussels: International Diabetes Federation; 2017. www. diabetesatlas.org. Accessed 20th February 2018.

2. Litwak L, Goh SY, Hussein Z, Malek R, Prusty V, Khamseh ME. Prevalence of diabetes complications in people with type 2 diabetes mellitus and its association with baseline characteristics in the multinational A1chieve study. Diabetol Metab Syndr 2013;5(1):57.

3. Chinenye S, Uloko AE, Ogbera AO, Ofoegbu EN, Fasanmade OA, Fasanmade AA, et al. profile of Nigerians with diabetes mellitus- Diabetes Care Nigeria Study Group (2008): results of a multicentre study. Indian J Endocrinol Metab 2012;16(4):558-64.

4. Moreno G, Mangione CM. Management of cardiovascular disease risk factors in older adults with Type 2 diabetes mellitus: 2002 2012 literature review. J Am Geriatr Soc 2013;61(11):2027-37.

5. Fisher L, Chesla CA, Bartz RJ. The family and type 2 diabetes: a framework for intervention. Diabetes Educ 1998;24:599-607.

6. Rosland A, Heisler M, Choi H. Family influences on self-management among functionally independent adults with diabetes or heart failure: do family members hinder as much as they help? Chronic Illn 2010;6:22-33.

7. Iloh G. Family functionality, medication adherence and blood glucose control among ambulatory Type 2 diabetic patients in a Nigerian hospital. J Basic Clin Pharm 2017;8:149-53. 
8. Adetunji A, Ladipo M, Irabor A, Adeleye J. Perceived family support and blood glucose control in type 2 diabetes. Diabetes 2007;15(2):18-9.

9. American Association of Diabetes Educators. AADE7 self-care behaviors. Diabetes Educ 2008;34:445-9.

10. American Diabetes Association. Standards of medical care in diabetes. Diabetes Care 2013;36(1):S1-66.

11. Welcome MO. The Nigerian Health care system: need for integrating adequate medical intelligence and surveillance system. $\mathrm{J}$ Pharm Bioallied Sci 2011;3(4):470-8.

12. dos Santos Costa R, Nogueira LT. Family support in the control of hypertension. Rev Lat Am Enfermagem 2008;16(5):871-6.

13. Mattson M, Hall JG. Linking health communication with social support. In: Mattson M, Hall JG, editors. Health as communication nexus: a service-learning approach. 1st ed. Dubuque: Kendall Hunt Publishing Company; 2011. pp. 181-218.

14. Dalton JM, Matteis M. The effect of family relationships and family support on diabetes self-care activities of older adults: a pilot study. Self Care Dependent Care Nurs 2014;21(11):12-22.

15. García-Huidobro D, Bittner M, Brahm P, Puschel K. Family intervention to control type 2 diabetes: a controlled clinical trial. Fam Pract 2011;28:4-11.

16. Kish L. Survey sampling. New York: John Wiley and Sons, Inc.; 1965.

17. Ajayi EA, Ajayi AO, Olalekan OE. Treatment to targets in type 2 diabetes mellitus: analysis of out-patients practice at a remote western Nigerian hospital. Internet J Med Update 2010:5(2):8-14.

18. Procidano ME, Heller K. Measures of perceived social support from friends and from family: three validation studies. Am J Community Psychol 1983;11(1):1-24.

19. American Diabetes Association. Diagnosis and classification of diabetes mellitus. Diabetes Care 2010;33(Suppl. 1):S62-9.

20. Odume BB, Ofoegbu OS, Aniwada EC, Okechukwu EF. The influence of family characteristics on glycemic control among adults with type 2 diabetes mellitus attending the general outpatient clinic, National Hospital Abuja, Nigeria. S Afr Fam Pract 2015;57(6):347-53.

21. Fasanmade OA, Dagogo-Jack S. Diabetes care in Nigeria. Ann Glob Health 2015;81(6):821-9.

22. Al-Akour N, Khader YS, Alaoui AM. Glycemic control and its determinants among patients with type- 2 diabetes mellitus attending a teaching hospital. J Diabetes Metab 2011;2(4):1-5.

23. Sobngwi E, Ndour-Mbaye M, Boateng K, Ramaiya K, Njenga E, Diop S, et al. Type 2 diabetes control and complications in specialised diabetes care centres of six sub-Saharan African countries: the Diabcare Africa study. Diabetes Res Clin Pract 2012;95(1):30-6.

24. International Diabetes Forum. The diabetes declaration and strategy for Africa: a call to action and plan of action to prevent and control diabetes and related chronic disease. IDF summary document; 2006 Nov. [cited 2013 Aug 9]. Available from: www.idf. org/webdata/docs/diabetes.

25. Ahmad NS, Islahudin F, Paraidathathu T. Factors associated with good glycemic control among patients with type 2 diabetes mellitus. J Diabetes Investig 2014;5(5):563-9.

26. Ali MK, Bullard KM, Imperatore G, Baker L, Gregg EW. Characteristics associated with poor glycemic control among adults with self-reported diagnosed diabetes-National Health and Nutrition Examination Survey, United States, 2007-2010. MMWR Suppl 2012;61(2):32-7.

27. Ewenighi CO, Uchechukwu D, Adejumo BI, Onyeanusi JC, Nnatuanyi NI, Onoh OG, et al. Responses to glycemic control therapy according to age, gender, level of adiposity and duration of diabetes in type 2 diabetic patients. Indian J Med Sci 2013;67:61-9.

28. Yuan S-P, Huang C-N, Liao H-C, Lin Y-T, Wang Y-h. Glycemic control outcomes by gender in the pay-for-performance system: a retrospective database analysis in patients with type 2 diabetes mellitus. Int J Endocrinol 2014;2014:575124.

29. Kautzky-Willer A, Kosi L, Lin J, Mihaljevic R. Gender-based differences in glycemic control and hypoglycaemia prevalence in patients with type 2 diabetes: results from patient-level pooled data of six randomized controlled trials. Diabetes Obes Metab 2015;17(6):533-40.

30. Hjelm K, Atwine F. Health-care seeking behavior among persons with diabetes in Uganda: an interview study. BMC Int Health Hum Rights 2011;11:11.

31. Swapna SK, Payghan BS, Mayuri RR, Kumara RC. Role of social determinants in glycemic control of type 2 diabetic subjects. Int Res J Med Sci 2014;2(4):2-6.

32. Ekane D. Contemporary family patterns in sub Saharan Africa. [Internet]. 2013. 7 p. Available from: http://urn.kb.se/resolve?urn =urn:nbn:se:su:diva-87303.

33. Armstrong N. The importance of extended families in the African American community: A qualitative analysis using social learning theory: Proceedings of the National Conference on Undergraduate Research (NCUR), 29-31 March 2012, Weber State University, Ogden, Utah. USA: UNC Asheville; 2013, p. 1322-7.

34. Okumagba PO. Family support for the elderly in delta state of Nigeria. Stud Home Community Sci 2011;5(1):21-7. 
35. Tobe SW, Kiss A, Szalai JP, Perkins N, Tsigoulis M, Baker B. Impact of job and marital strain on ambulatory blood pressure: results from the double exposure study. Am J Hypertens 2005;18(8):1046-51.

36. Wichit N, Mnatzaganian G, Courtney M, Schulz P, Johnson M. Randomized controlled trial of a family-oriented self-management program to improve self-efficacy, glycemic control and quality of life among Thai individuals with type 2 diabetes. Diabetes Res Clin Pract 2017;123(2017):37-48.

37. Joan AV, Exebio JC, Zarini GG, Huffman FG. The role of family/ friend social support in diabetes self-management for minorities with type 2 diabetes. World J Nutr Health 2014;2(1):1-9.
38. Pamungkas RA, Chamroonsawasdi K, Vatanasomboon P. A systematic review: family support integrated with diabetes self-management among uncontrolled type II diabetes mellitus patients. Behav Sci 2017;7(62):1-17.

39. Eun SK, Seong JL, Ohk HR, Jee YL, Hyun SY, Moon GC. The relationship of family support with blood glucose control in elderly type 2 diabetic patients. J Kor Diabetes Assoc 2017;31(5):435-43.

40. Makinwa-Adebusoye P. Socio-cultural factors affecting fertility in sub Saharan Africa. Lagos: The Nigerian Institute of Social and Economic Research; 2001. 